\title{
The Ability of a Weakly Compressible Solver to Predict Landing Gear Noise with Flow-Acoustic Interactions
}

\author{
Yu Hou ${ }^{1}$ and David Angland ${ }^{2}$ \\ Faculty of Engineering and the Environment, \\ University of Southampton, Southampton, SO16 7QF, UK \\ Aline Scotto $^{3}$ \\ Acoustics Department, AIRBUS Operations SAS, \\ 316 route de Bayonne, 31060 Toulouse Cedex 09, France
}

\begin{abstract}
The ability of a weakly compressible solver to solve landing gear noise with flow-acoustic coupling is investigated. Traditionally compressible flow solvers are used to simulate flowacoustic coupling. However, compressible solvers require greater computational resources compared to incompressible solvers at low Mach numbers such as an aircraft on approach to landing. While incompressible solvers are able to capture the steady aerodynamics, in this work, their inability to capture the correct wall pressure spectra and far-field acoustics is demonstrated for a relatively simple two wheel landing gear, i.e. the LAGOON (Landing Gear Noise database for CAA validation) \#1 geometry. This is due to the inability of incompressible solvers to capture cavity resonances, which are important contributors to not only tonal but also broadband noise. This is significant for landing gear noise predictions. A weakly compressible solver is tested to determine its ability to resolve the flow-acoustic coupling for a low Mach number flow. This solver has a similar computational cost to an incompressible solver. The simulations are performed using a weakly compressible solver added to OpenFOAM with a one-equation Large-Eddy Simulation model. An incompressible simulation of the same configuration is also performed for comparison. Results shows that the weakly compressible solver can correctly solve the resonant tonal and broadband noise that are absent in the solution from the incompressible solver. The weakly compressible solver maintains similar behaviour in predicting the timeaveraged and root-mean-square flow variables. A grid sensitivity study is also included, and consistency is compared between the two meshes of different resolutions for both near-field pressure fluctuations and far-field acoustics. The computational cost of the weakly compressible method for landing gear simulations is slightly less than the incompressible solver and significantly less than other fully compressible Navier-Stokes solvers.
\end{abstract}

\section{Nomenclature}

$\begin{array}{lll}C_{p} & =\text { Time-averaged pressure coefficient } \\ c_{0} & =\text { Ambient speed of sound, } \mathrm{m} / \mathrm{s} \\ D & =\text { Diameter, } \mathrm{m} \\ f & =\text { Frequency, } \mathrm{Hz} \\ k_{S G S} & =\text { Sub-grid scale turbulent kinetic energy, } \mathrm{m}^{2} / \mathrm{s}^{2} \\ L & =\text { Spacing, metre } \\ M & =\text { Mach number } \\ v_{S G S} & =\text { Sub-grid scale eddy viscosity } \\ p & =\text { Pressure, Pa } \\ p^{\prime} & =\text { Pressure perturbation, } \mathrm{Pa} \\ R e & =\text { Reynolds number } \\ \rho & =\text { Density, } \mathrm{kg} / \mathrm{m}^{3} \\ \rho^{\prime} & =\text { Density perturbation, } \mathrm{kg} / \mathrm{m}^{3}\end{array}$

\footnotetext{
${ }^{1}$ PhD student, Airbus Noise Technology Centre, yh25g11@soton.ac.uk.

${ }^{2}$ Associate Professor, Airbus Noise Technology Centre, AIAA Member, d.angland@soton.ac.uk.

${ }^{3}$ Acoustic engineer, Acoustics Department, Airbus.
} 


$\begin{array}{lll}S & =\text { Span, } \mathrm{m} \\ U_{i}, U_{j} & =\text { Velocity, } \mathrm{m} / \mathrm{s} \\ U_{\infty} & =\text { Free-stream velocity, } \mathrm{m} / \mathrm{s} \\ y_{1}^{+} & =\text {Thickness of the first-layer mesh off solid surface in wall unit }\end{array}$

$\begin{array}{ll}\text { BANC } & =\text { Benchmark problems for Airframe Noise Computations } \\ \text { CFD } & =\text { Computational Fluid Dynamics } \\ \text { CWF } & =\text { Fomposite Wall Function } \\ \text { FW-H } & =\text { Hotwire } \\ \text { HW } & =\text { Incompressible } \\ \text { ICMP } & =\text { Lattice Boltzmann Method } \\ \text { LBM } & =\text { Laser Doppler Velocimetry } \\ \text { LDV } & =\text { Large-Eddy Simulation } \\ \text { LES } & =\text { Pressure Implicit with Split Operator } \\ \text { PISO } & =\text { Particle Image Velocimetry } \\ \text { PIV } & =\text { Root-Mean-Square } \\ \text { PSD } & =\text { snappyHexMesh mesh } \\ \text { RMS } & =\text { Weakly compressible } \\ \text { SNP } & =\text { Wall-Modelled Large-Eddy Simulation } \\ \text { WCMP } & \end{array}$

\section{Introduction}

$\mathrm{N}_{\mathrm{o}}^{\circ}$ oise from landing gears has been identified to be one of the main contributors to the overall airframe noise of a civil aircraft, especially in the approach and landing phase. To reduce the overall aircraft noise, studies on the noise generation mechanisms of landing gear are of vital importance.

Computational Fluid Dynamics (CFD) has been extensively used to as a tool to study the turbulent flow field around landing gears and the corresponding noise generation process in the past fifteen years ${ }^{12}{ }^{3} 4$. Some of these studies have been performed solving the incompressible Navier-Stokes equations. As well as the noise generated by turbulence in the vicinity of a solid landing gear surface, flow-acoustic coupling phenomenon also exists for landing gears. Examples of this coupling include landing gear bay cavities, wheel rim cavities, and small pin holes. These cavities vary over a wide range of dimensions and shapes, and their contribution to the far-field sound cannot be neglected ${ }^{56}$.

Traditionally, the flow-acoustic coupling can be solved by fully compressible simulations ${ }^{567}$. In these studies, the compressible Navier-Stokes equations are solved, thus the coupling between the flow and acoustics in the near field is explicitly captured. However, this approach is more expensive than its incompressible counterpart for low Mach number flows, due to two main reasons. Firstly, an additional transport equation accounting for energy conservation must be solved. Secondly, at low Mach numbers the so-called stiffness problem is known to lead to an inefficient and inaccurate implementation of most conventional CFD schemes ${ }^{8}$.

In this work, a weakly compressible formulation is applied to determine its accuracy for aeroacoustic problems involving flow-acoustic coupling. The weakly compressible formulation was first derived by Inagaki et al ${ }^{9}$ for rectangular cavity noise. An assumption of the weak compressible effect was used for correlating the perturbation of pressure from the atmosphere pressure, with a modification to the continuity equation. Their simulation results agreed well with experimental data. This formulation was later implemented into the commercial flow solver FLUENT by Wang et $\mathrm{al}^{10}$ using a User Defined Function (UDF) to study cavity noise using a Large-Eddy Simulation (LES). It allowed a reasonable prediction of modal resonant frequencies that were in good agreement with the Rossiter formula. Even though some success has been achieved with such weakly compressible solvers, their ability to correctly predict aeroacoustic phenomenon of more complex landing gear geometries remains unclear. Therefore, a study to investigate the accuracy and efficiency of this weakly compressible equation set, applied to landing gear aeroacoustics, was performed.

This paper is organised as follows. In Section II the numerical approaches, including the weakly compressible solver, turbulence modelling and meshes are summarised. Section III describes the experimental and numerical setups for the LAGOON \#1 landing gear. In Section IV the predictions of both near-field turbulence and far-field acoustics using the weakly compressible numerical approach are presented and analysed. Section V summarises the current findings and proposes future work for this study. 


\section{Numerical approaches}

\section{II.A Weakly compressible equations}

At very low Mach numbers, Inagaki et al ${ }^{9}$ derived a set of equations that accounts for the compressibility for high-Reynolds-number flows without a significant heat source,

$$
\begin{gathered}
\frac{1}{c_{0}^{2}}\left[\frac{\partial p}{\partial t}+U_{j} \frac{\partial p}{\partial x_{j}}\right]+\frac{\partial U_{j}}{\partial x_{j}}=0, \\
\frac{\partial U_{i}}{\partial t}+U_{j} \frac{\partial U_{i}}{\partial x_{j}}=-\frac{1}{\rho} \frac{\partial p}{\partial x_{i}}+\frac{\partial}{\partial x_{j}}\left[\frac{1}{v}\left(\frac{\partial U_{i}}{\partial x_{j}}+\frac{\partial U_{j}}{\partial x_{i}}\right)\right] .
\end{gathered}
$$

These equations make three assumptions. The first is that the density perturbation $\rho^{\prime}$ is much smaller than the mean value $\rho$ so that $1 /\left(1+\rho^{\prime} / \rho\right) \rightarrow 1$. The second assumption is that the entropy is constant so that the pressure perturbation $p^{\prime}$ can be related to density perturbation $\rho^{\prime}$ via the constant ambient speed of sound $c_{0}$ by $c_{0}^{2}\left(D \rho^{\prime} / D t\right)=D p^{\prime} / D t$. The third assumption is that the effects of the normal stress terms are negligibly small compared to the shear stress terms in low-Mach-number flows. Note that equations (1) and (2) are dimensional instead of their original non-dimensional form by Inagaki et al ${ }^{9}$. The new continuity equation is now a transport equation for pressure $p$, and the divergence of velocity serves as a source/sink term for the pressure.

In order to solve equation (1) and (2) the PISO algorithm is used with a modified form for momentumpressure coupling to implement these weakly compressible equations. The discretised momentum equation (2) can be written as,

$$
[A] U_{j}+[H]=-\frac{1}{\rho} \frac{\partial p}{\partial x_{j}}
$$

where $[A] U_{i}$ and $[H]$ are the diagonal and non-diagonal elements of a linear system. Therefore, the divergence of velocity can be written as,

$$
\frac{\partial U_{j}}{\partial x_{j}}=-\left[\frac{1}{\rho} \frac{\partial}{\partial x_{j}}[A]^{-1} \frac{\partial p}{\partial x_{j}}+\frac{\partial}{\partial x_{j}}[A]^{-1}[H]\right] .
$$

Substituting the continuity equation (1) into equation (4) the modified pressure equation can be expressed as,

$$
\frac{1}{c_{0}^{2}}\left(\frac{\partial p}{\partial t}+U_{j} \frac{\partial p}{\partial x_{j}}\right)=\frac{1}{\rho} \frac{\partial}{\partial x_{j}}[A]^{-1} \frac{\partial p}{\partial x_{j}}+\frac{\partial}{\partial x_{j}}[A]^{-1}[H] .
$$

In the weakly compressible solver, the momentum equation (2) is identical to an incompressible solver, while the Poisson pressure equation in the PISO (Pressure Implicit with Split Operator) algorithm ${ }^{11}$ is modified to include the time derivative and convection of pressure. The original Poisson equation for the incompressible solver can be recovered in the limit as $c_{0}$ approaches infinite (i.e. an incompressible flow).

\section{II.B Turbulence modelling and wall treatments}

In the current study, a one-equation LES model by Yoshizawa and Horiuti ${ }^{12}$ is used to model the sub-grid scale turbulence. This model solves a transport equation of sub-grid turbulent kinetic energy $k_{S G S}$ simultaneously, and sub-grid scale eddy viscosity $v_{S G S}$ is calculated explicitly from the solution of $k_{S G S}$.

In order to reduce the computational resources required to resolve the viscous sub-layer imposed by wallresolved LES, a wall-modelled LES (WMLES) approach is applied. The composite wall function derived by Afzal ${ }^{13}$ is applied to bridge the viscous sublayer. This wall function is able to account for effect of pressure gradient, both favourable and adverse, on the outer boundary layer variables. Compared to the standard log-law wall function, this approach is more suitable for turbulent flow around bluff bodies, where pressure gradients have an important effect on boundary layer separation and the resultant separated flow. Hou et al. ${ }^{14}$ applied this WMLES methodology to single and tandem circular cylinders, and satisfactory results were obtained for both near-field turbulence and far-field acoustics. 


\section{II.C Solvers and meshing tools}

For the present simulations, the open source, cell-centred, unstructured, finite volume CFD solver OpenFOAM ${ }^{15} 16$ is used for solving the governing weakly compressible Navier-Stokes equations. The modified PISO algorithm, as described in Section II.A, is added to a new solver for pressure-momentum coupling. The composite wall function is also implemented into the solver to treat the boundary layer. A second-order, limited central scheme is used for gradient terms. Second-order, blended schemes that combine upwind schemes and central schemes are applied for divergence terms. The backward scheme is adopted to achieve second-order accuracy in time-stepping. All simulations were run on University of Southampton's Linux cluster Iridis4. Each node of the cluster has $162.6 \mathrm{GHz}$ cores, and each core has $4 \mathrm{~GB}$ memory. Pressure signals on the solid surfaces are sampled and the far-field noise is calculated by solving Curle's equation using a Ffowcs-Williams and Hawkings (FW-H) solver.

\section{Experimental and Numerical Setup}

\section{III.A Wind tunnel tests of LAGOON \#1landing gear}

The LAGOON \#1 landing gear is a highly simplified, 40\%-scale A320 nose landing gear without fuselage or landing gear bay. The landing gear consists of a cylindrical strut, cylindrical axles and two wheels. The geometry also features two cylindrical cavities facing each other on the inboard sides of both wheels. The wheels have a diameter of $0.3 \mathrm{~m}$ and the strut has a length of $0.69 \mathrm{~m}$ and is mounted on a profiled base.

The landing gear has been tested both in the closed-section ONERA aerodynamic wind tunnel F2 (F2) and in an open-jet, anechoic ONERA aeroacoustic wind tunnel CEPRA19 (C19). In both experiments ZIG-ZAG tape has been used on upstream face of the wheels and CAD-CUT strips have been used on legs and axles, for the purpose of triggering transition of the boundary layer into a turbulent state.
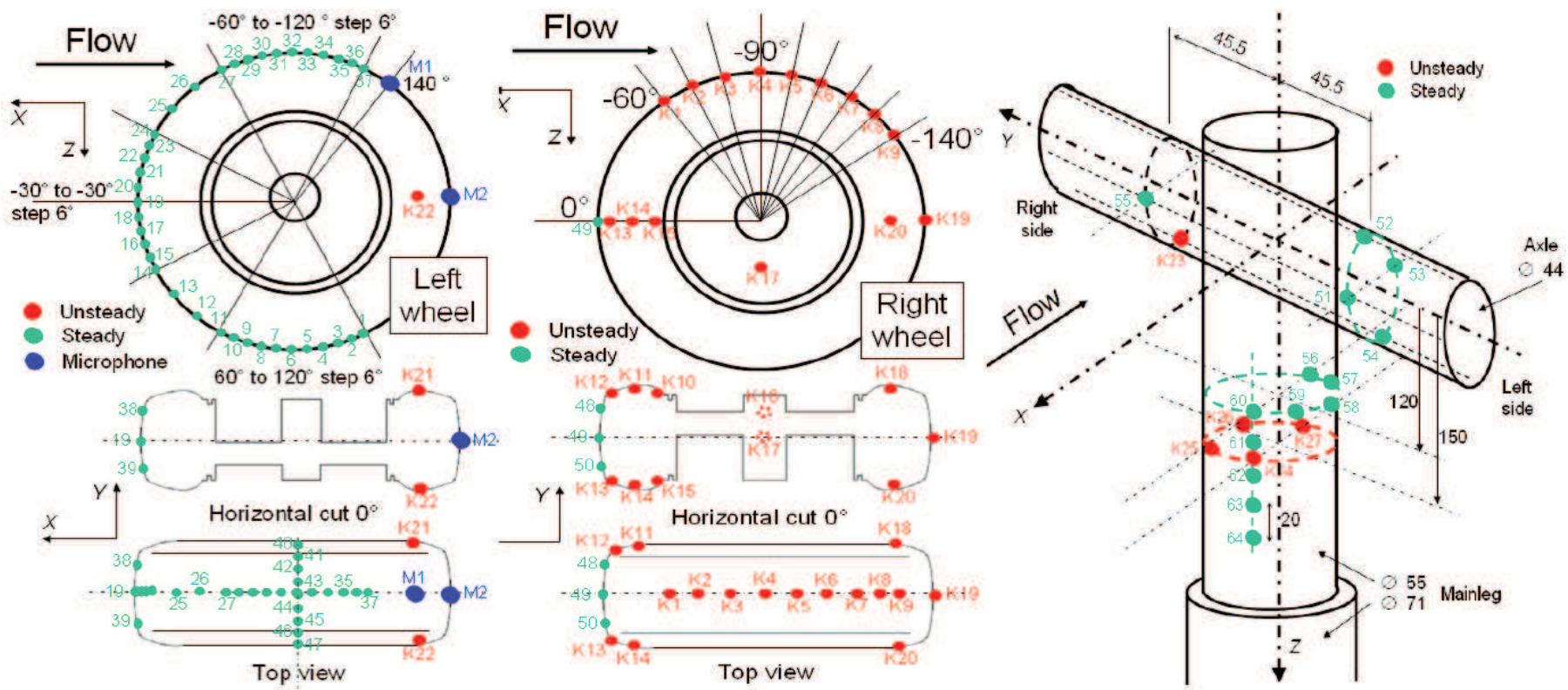

Figure 1 Location of mean pressure taps and unsteady pressure Kulites ${ }^{17}$.

Extensive aerodynamic and acoustic measurements have been performed in both facilities, providing the validation database for this study. Steady and unsteady wall pressures have been sampled on 64 pressure taps and 27 Kulites, as shown in Figure 1. The near-field turbulent flow field was measured using Hotwire anemometry (HW), Particle Image Velocimetry (PIV) and Laser Doppler Velocimetry (LDV). Furthermore, in the $\mathrm{C} 19$ facility, far-field acoustic measurements were performed, on two circular microphone arrays centred at the axle midpoint. The first was placed on the symmetry plane as the 'flyover' array and the second was rotated by $56^{\circ}$ around the $x$ axis forming a 'sideline' array. Both arrays were located $20 D$ from the axle centre, where $D$ is the wheel diameter, covering an angular range between $30^{\circ}$ (downstream) and $140^{\circ}$ (upstream). A shear layer refraction correction by Amiet and an atmospheric absorption correction have been applied to these acoustic data. Numerical predictions and experimental measurements of this configuration were summarised by Manoha and Caruelle ${ }^{18}$ for the third workshop of Benchmark problems of Airframe Noise Computations (BANC-III). 


\section{III.B Numerical setup}

The dimensions of the computational domain were identical for all simulations. The inflow and outflow boundaries were placed $6.0 \mathrm{D}$ upstream and $10.0 \mathrm{D}$ downstream of the axle midpoint respectively. The vertical measurement of the computational domain was 8 times the wheel diameter. The computational domain extends $6.4 D$ in spanwise direction.

In order to study the effect of grid sensitivity two meshes of different sizes were studied. Both meshes were generated by OpenFOAM's snappyHexMesh utility. The background mesh consists of cubic cells and its refinement level was defined as 0 . The edge length of cells in level $n+1$ was half of the edge length of cells in level $n$. The maximum refinement level was 7 , which was used close to the landing gear surface and in the nearwake region. The coarse mesh (Mesh C) and fine mesh (Mesh F) consist of $4.91 \times 10^{6}$ and $21.82 \times 10^{6}$ cells respectively. Both meshes are generated using the same refinement regions and levels. At the same refinement level, the cell size in Mesh F is $60 \%$ of that in Mesh C. Therefore, in the finest region, the sizes of the cells are $1.25 \times 10^{-3} \mathrm{~m}$ and $0.75 \times 10^{-3} \mathrm{~m}$, which corresponds to $1 / 240 \mathrm{D}$ and $1 / 400 \mathrm{D}$ for the coarse mesh (Mesh C) and the fine mesh (Mesh F) respectively. One layer of boundary-fitted cells was also added to all components with a thickness of $1 / 300 D$, achieving a $y_{1}^{+} \approx 100$ at the cell centre.

The freestream velocity was $78 \mathrm{~m} / \mathrm{s}$ at the inflow boundary, which is identical to the wind tunnel experiments, resulting in a Reynolds number of $1.56 \times 10^{6}$ based on the wheel diameter $D=0.30 \mathrm{~m}$. For the weakly compressible simulation the constant speed of sound was $340 \mathrm{~m} / \mathrm{s}$, resulting in a free-stream Mach number of 0.23 . No-slip boundary conditions were applied to all landing gear components and the streamlined supporting base. The WMLES approach described in Section II.B forces the boundary layer to be fully turbulent. Pressure outlet boundary conditions were applied to the outflow boundary. The side walls as well as the upper and lower boundaries of the computational domain were modelled as slip walls. The non-dimensional simulation time step $\Delta t U_{\infty} / D$ was $6.5 \times 10^{-4}$, yielding approximately 267 time steps per period for the second cavity tone at a frequency at $1.5 \mathrm{kHz}$. The simulation was run $8 \times 10^{4}$ time steps $(0.2 \mathrm{~s}$ of physical time $)$ to stabilize the flow field from a potential flow solution, after which $16 \times 10^{4}$ time steps $(0.4 \mathrm{~s}$ of physical time $)$ were run to obtain the mean properties of the flow field. For the last $8 \times 10^{4}$ time steps $(0.2 \mathrm{~s}$ of physical time $)$ time resolved pressures on all the landing gear components were sampled for an FW-H calculation of the farfield acoustics.

Three different simulations were performed in the current study. Weakly compressible simulations (WCMP) were performed on both the coarse and fine meshes for a grid sensitivity study. Meanwhile an incompressible simulation (ICMP) was performed using the fine mesh, in order to investigate the effects of adding weak compressibility on aerodynamic and acoustic predictions and computational costs. The computations are performed on Iridis 4 cluster at the University of Southampton with 16 cores (256 processors) with 32GB memory being distributed to each core.

\section{Numerical Results}

\section{IV.A Mean wall pressure}

Figure 2 presents the time-averaged pressure coefficients on different pressure probe locations on the landing gear surface. The agreement with the experimental data is excellent on the wheels, both along the circumferential line (Figure 2 (a)) and on other pressure taps (No. 38 - No. 51 in Figure 2 (b)). Reasonable agreement is obtained on the axle (No. 52 - No. 55 in Figure 2 (b)) and on the strut (No.56 - No.64 in Figure 2 (b)). Predictions given by both meshes are quite close to each other, with minor differences on the rear face of the wheels.

The differences between the weakly compressible and incompressible predictions of the time-averaged pressure coefficient on the landing gear surface are also shown in Figure 2. On the wheels (Figure 2 (a) and No. 38-51 in Figure 2 (b)), excellent agreement with experimental measurements is obtained by both solvers. Around $120^{\circ}$, the incompressible simulation predicted a slightly earlier separation point, which is not seen in both weakly compressible results. Some minor differences are observed on the rear face of the wheel. There are larger discrepancy between the two different solvers on the circumferential line on the axle (No. 52 - No.55 in Figure 2 (b)) and strut (No. 56 - No.60 in Figure 2 (b)). Also, the weakly compressible solver predicted a larger suction on the upstream faces of both axle and lower strut, suggesting higher flow velocity in the region between the wheels. As a result, the base pressure on rear face of the lower strut was lower and closer to the experimental measurements for the weakly compressible results. In general, the weakly compressible predictions are closer to wind tunnel data. The weakly compressible solver is slightly favoured over the incompressible solver for the mean pressure predictions. 


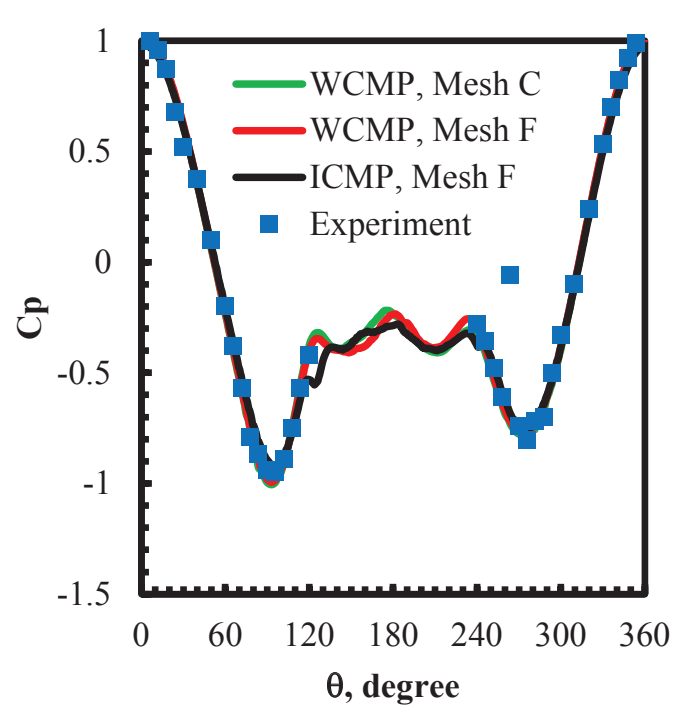

(a)

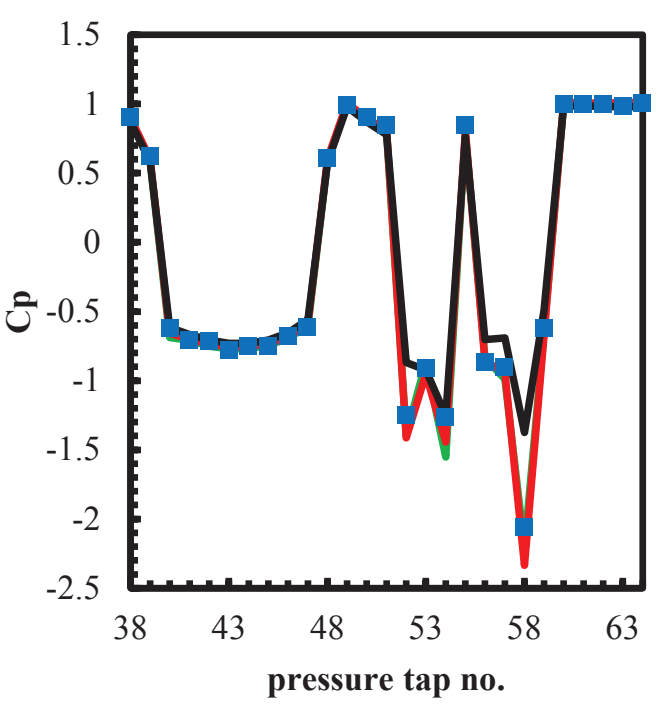

(b)

Figure 2 Time-averaged pressure coefficients on landing gear surface:

(a) along wheel circumferential line, (b) other pressure taps. Location of pressure taps is shown in Figure 1.

\section{IV.B Unsteady wall pressure}

Figure 3 shows the Power Spectral Density (PSD) of unsteady pressure signals for six Kulite sensors shown in Figure 1. Major differences in the spectra between the weakly compressible and incompressible solutions are found at Kulite locations where obvious cavity tones exist in the experimental data (e.g. Kulites 1, 15, 23 and 25). These tonal peaks are completely absent in the incompressible predictions, indicating the incompressible solver is incapable of capturing the correct physics of resonant noise for this configuration. This is expected, since the incompressible assumption forces a divergence-free flow and an infinite speed of sound, so that all responses are instantaneous, leading to an infinite resonant frequency. Besides the tones, the broadband contents at Kulites 1, 15, 23 and 25 were also severely under-predicted by the incompressible simulation. Since all these Kulites are located in an attached flow region, the broadband contents are very likely to be noise propagated from other areas, instead of turbulence-induced pressure fluctuations. The absence is suspected to be caused by the incompressible solvers inability of resolving propagation of acoustic waves and/or its failure to simulate some broadband noise generation processes by flow-acoustic coupling. At Kulites 17 and 19, where separated turbulent flow exists, the weakly compressible and incompressible results are quite close to each other, indicating the weakly compressible solver is equally as capable as the incompressible solver in predicting unsteady pressure fluctuation generated by the separated flow. Even though the results shown here are limited, it strongly suggests that including weakly compressible effects into the simulations would provide major advantages over a purely incompressible approach. In fact, it poses a question whether pure incompressible solvers are appropriate for landing gear noise predictions, especially when flow-acoustic coupling phenomena are among the significant noise generation processes.

Kulite 1 is located in the mid-span plane of the wheel and downstream of the zig-zag strip in the attached flow region. Reasonable agreement was obtained by the weakly compressible solver below $2.0 \mathrm{kHz}$, with two small peaks at about $1.0 \mathrm{kHz}$ and $1.5 \mathrm{kHz}$ that are correctly captured. Above $2.0 \mathrm{kHz}$, a fast roll-off can be observed for the numerical predictions while experimental spectrum remains above $80 \mathrm{~dB}$. Other researchers ${ }^{719}$ have also found similar results, since the small local turbulent scales induced by the zig-zag strip that result in transition cannot be captured by the fully turbulent treatment of boundary layer in the numerical simulations.

At Kulite 15 located upstream of the wheel cavity, tones around $1.0 \mathrm{kHz}$ and $1.5 \mathrm{kHz}$ were captured by both the coarse (Mesh C) and fine (Mesh F) meshes. The frequencies of the predicted tones are at $1000 \mathrm{~Hz}$ and 1460 $\mathrm{Hz}$ (bandwidth $20 \mathrm{~Hz}$ ), which are slightly lower than experimental measurements $(1030 \mathrm{~Hz}$ and $1510 \mathrm{~Hz}$ with a bandwidth of $10 \mathrm{~Hz}$ ). The simulation using the coarse mesh overestimated the amplitude of the first peak, and it was improved by using the finer mesh with increased resolution. The frequencies from which the simulation starts to under-predict compared to the experiments are relatively low. They are found to be $1.7 \mathrm{kHz}$ and 2.2 $\mathrm{kHz}$ for the coarse and fine mesh respectively. 

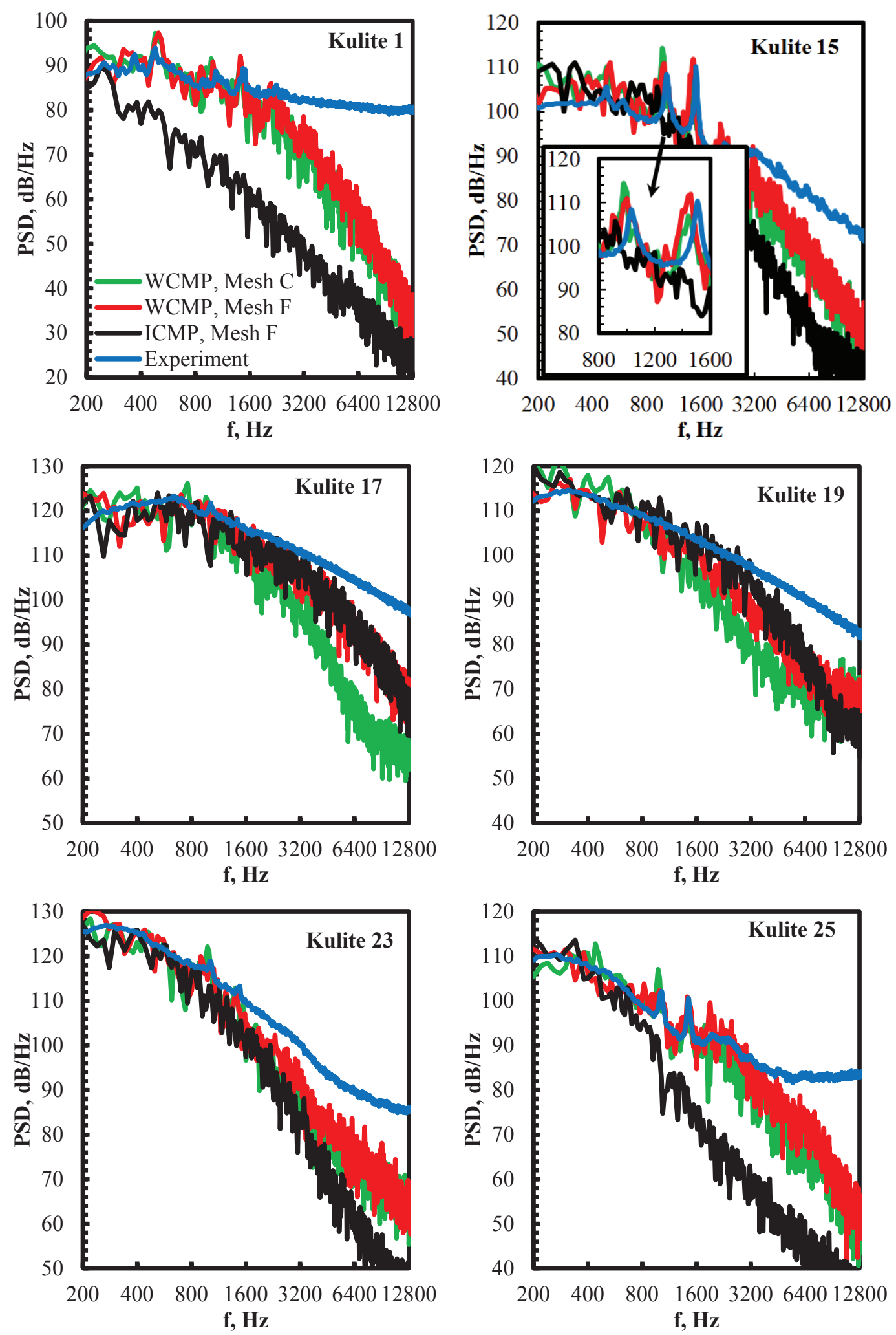

Figure 3 Power spectral density of unsteady pressure signals at Kulite locations given in Figure 1.

At Kulite 17, which is in the internal cavity of the right wheel at $X=0$, the spectra are fully broadband in nature due to separated turbulence in the cavity. Predictions are in reasonable agreement with the experimental measurements before the mid-frequency roll-off around $1.1 \mathrm{kHz}$ and $1.7 \mathrm{kHz}$ for the coarse and fine resolution respectively. Similarly at Kulite 19 on the rear face of the wheel, broadband spectra are predicted by weakly compressible solver using both coarse and fine meshes, and less mid- and high-frequency content was obtained 
by the coarse mesh. At both locations, no tonal peaks are observed for both the numerical simulations and the wind tunnel experiments.

Kulite 23 is on the axle close to the separation point. Two subtle tonal peaks at approximately $1.0 \mathrm{kHz}$ and $1.5 \mathrm{kHz}$ are correctly captured by the weakly compressible solver using both the fine and coarse mesh. However, the broadband contents of the wall pressure decrease faster above $1.0 \mathrm{kHz}$ in the weakly compressible simulations compared to the experiments, thus are under-predicted in mid and high frequency range. It is suspected that the relatively low resolution in this region $\left(0.75 \times 10^{-4} \mathrm{~m}\right.$ for Mesh F and $1.25 \times 10^{-3} \mathrm{~m}$ for Mesh C) is not sufficiently fine to capture the small turbulent structures that are responsible for the pressure fluctuations in this frequency range.

At Kulite 25, the tones are visible for both the experimental data and numerical predictions. Again the coarse mesh over-predicted the amplitude of the first tone at Kulite 15 and this was improved by using the refined mesh. Above the second tonal frequency the broadband noise level was also well captured, till the roll-off frequencies, which are $2.0 \mathrm{kHz}$ for the coarse mesh and $3.0 \mathrm{kHz}$ for the fine mesh.

\section{IV.C Flow field in wake region}
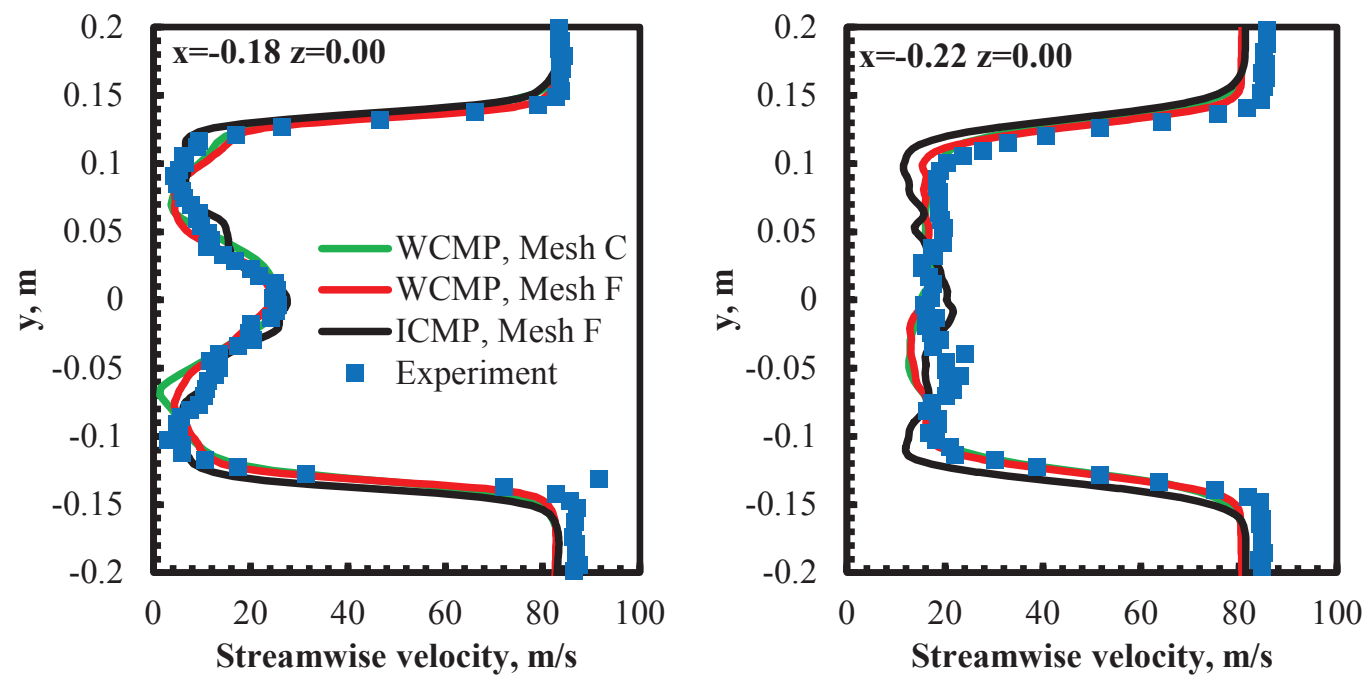

Figure 4 Time-averaged streamwise velocity.
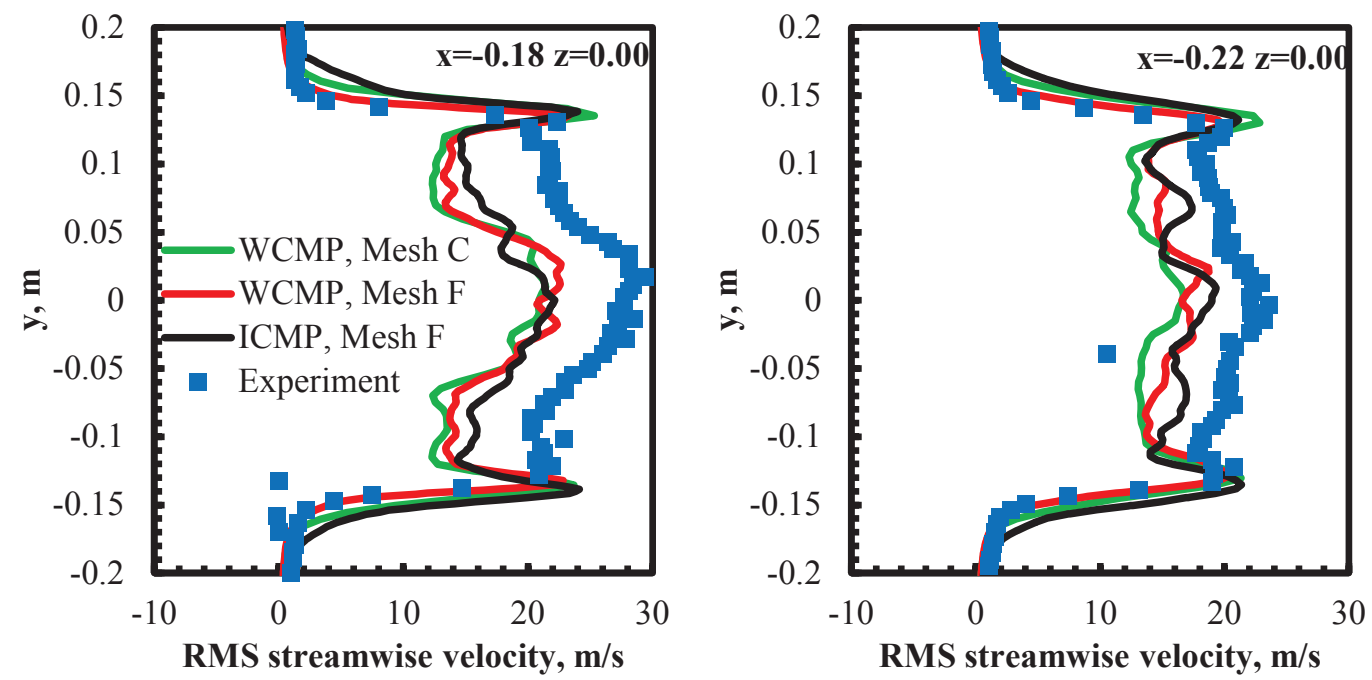

Figure 5 RMS streamwise velocity. 
Figures 4 and 5 compare the predicted time-averaged and Root-Mean-Square (RMS) streamwise velocities with the experimental measurements, along different profiles in the wake region downstream of the landing gear. A certain level of asymmetry is observed in both the experimental measurements and numerical predictions. The time-averaged velocity predictions are in good agreement with the experiments, in terms of wake width and velocity deficit in the wake region. In contrast, the RMS predictions are found to have larger discrepancies when compared to the wind tunnel tests. Two sharp peaks of RMS values are predicted at both edges of the wake. The amplitudes of the peaks were slightly over-predicted by the simulations. Between the two peaks the RMS velocities were under-predicted. Similar results were also obtained by other research groups using either traditional Navier-Stokes solvers ${ }^{7}$ or Lattice Boltzmann solvers ${ }^{19}$.

For these results at these locations, the weakly compressible and incompressible predictions are very similar qualitatively and quantitatively for both mean and RMS values, except that incompressible solution predicted a slightly wider wake. The under-estimation of RMS value inside the wake is found both for the weakly compressible and incompressible results.

\section{IV.D Far-field acoustics}

Figures 8, 9 and 10 present the spectra of far-field noise, obtained using an FW-H solver, at Microphone 3, 6 and 9 respectively, on both the flyover and sideline arcs as shown in Figure 6. In general, the weakly compressible predictions are in reasonable agreement with the experiments. Tonal peaks are not found at all flyover microphones. At sideline microphones, peaks at approximately $1.5 \mathrm{kHz}$ were captured by the weakly compressible solutions. In contrast, at all microphone locations, the incompressible predictions constantly under-predicted the broadband noise level by $5 \mathrm{~dB}$ to $10 \mathrm{~dB}$, compared to the weakly compressible solutions and experimental measurements. This demonstrates that for a configuration where flow-acoustic coupling exists and is an important contributor to the overall sound, an incompressible solver is not an appropriate option.
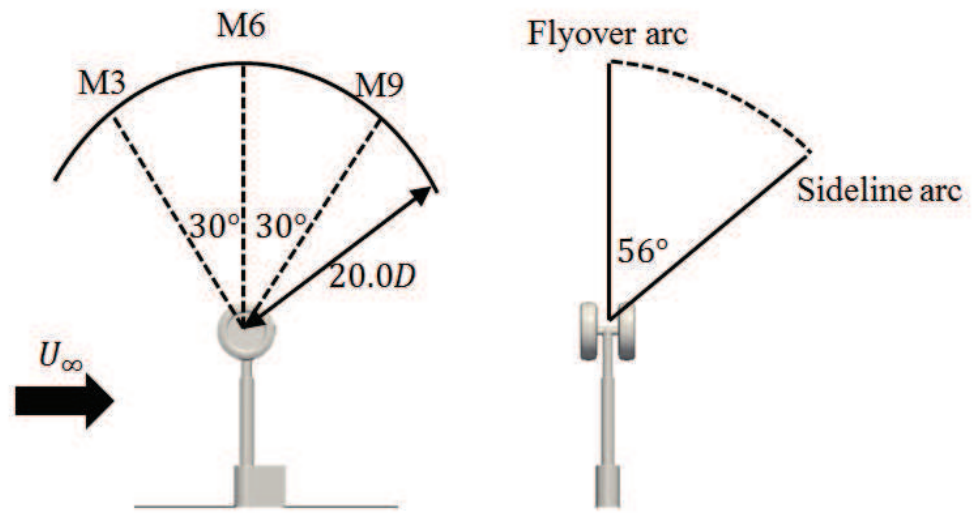

Figure 6 Locations of far-field microphone locations.

At Microphone 3, the fine mesh (Mesh F) over-predicted the far-field noise level by around $3 \mathrm{~dB}$ between $0.7 \mathrm{kHz}$ and $6.0 \mathrm{kHz}$ on the flyover arc and by $4 \mathrm{~dB}$ between $0.7 \mathrm{kHz}$ and $2.2 \mathrm{kHz}$ on the sideline arc. It also includes the over-predicted cavity resonant peak by about $4 \mathrm{~dB}$. Predictions using the coarse mesh (Mesh $\mathrm{C}$ ) also suffer a slight over-prediction by about $2 \mathrm{~dB}$ between $0.7 \mathrm{kHz}$ and $1.5 \mathrm{kHz}$ by about $2 \mathrm{~dB}$ on flyover arc and between $0.7 \mathrm{kHz}$ and $1.5 \mathrm{kHz}$ on sideline arc including the cavity tone. Outside these frequency ranges, the numerical predictions are in excellent agreement with the experimental data up to highest frequency in the figures, i.e. $12.8 \mathrm{kHz}$.

Microphone 6 is located at an overhead position on both the flyover and sideline arcs. Excellent agreement with the experimental measurements is found for both weakly compressible predictions, below $2.0 \mathrm{kHz}$ and 3.9 $\mathrm{kHz}$ for Mesh $\mathrm{C}$ and Mesh F respectively on the flyover arc and below $2.5 \mathrm{kHz}$ and $4.5 \mathrm{kHz}$ for Mesh $\mathrm{C}$ and Mesh F on the sideline arc. Over these frequencies, the numerical predictions roll-off slightly faster than the wind tunnel measurements towards the high-frequency, leading to an under-prediction that is more severe for the flyover microphone location.

At microphone location 9, the cut-off frequencies of the weakly compressible predictions are found to be lower than those at the overhead microphone (Microphone 6), namely $1.7 \mathrm{kHz}$ and $1.9 \mathrm{kHz}$ for Mesh $\mathrm{C}$ and Mesh F respectively on the flyover arc, and $2.2 \mathrm{kHz}$ and $3.8 \mathrm{kHz}$ for Mesh $\mathrm{C}$ and Mesh F respectively on the sideline arc. Below these frequencies results obtained by the weakly compressible simulations using both meshes are in excellent agreement with the experimental measurements. Similarly, the roll-off takes place earlier with more severe under-prediction on the flyover arc. 


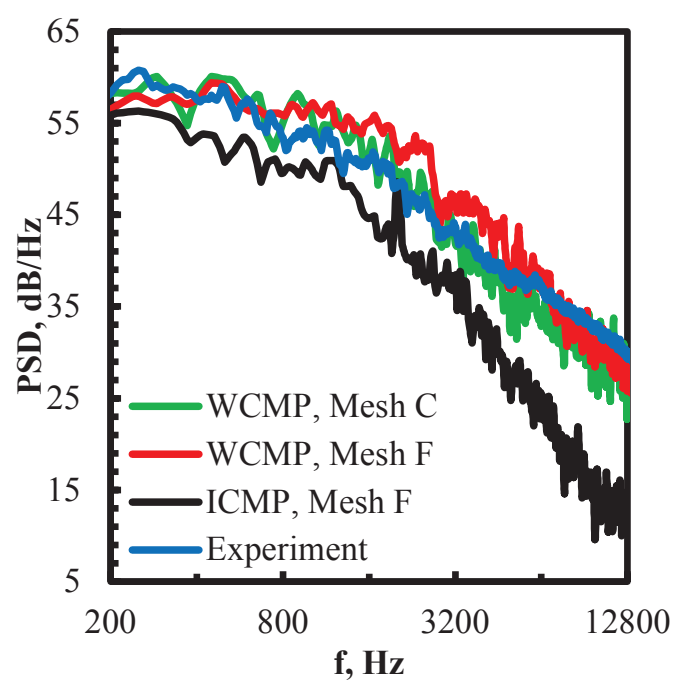

(a)

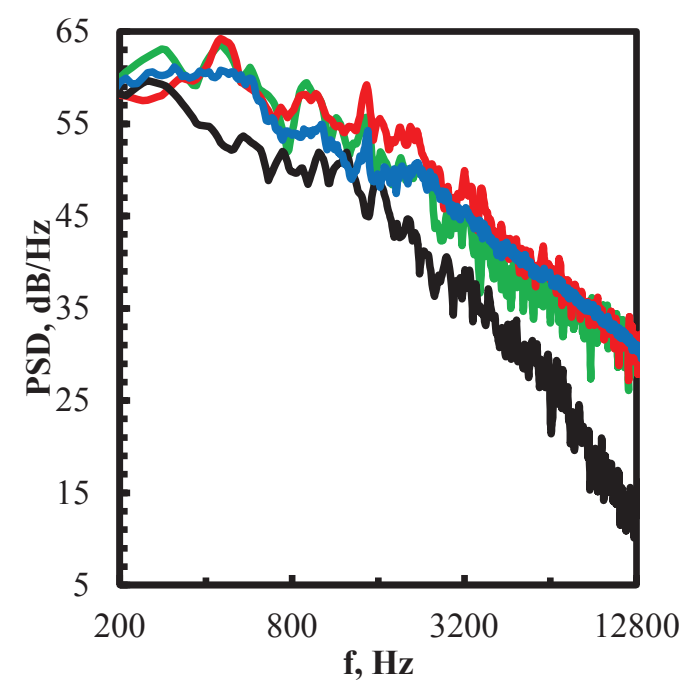

(b)

Figure 7 Power spectral density at Microphone 3: (a) flyover arc, (b) sideline

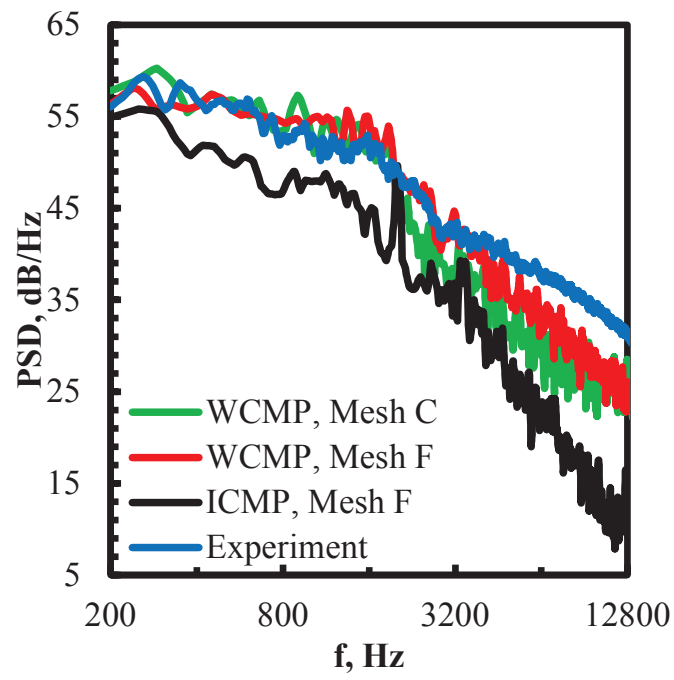

(a)

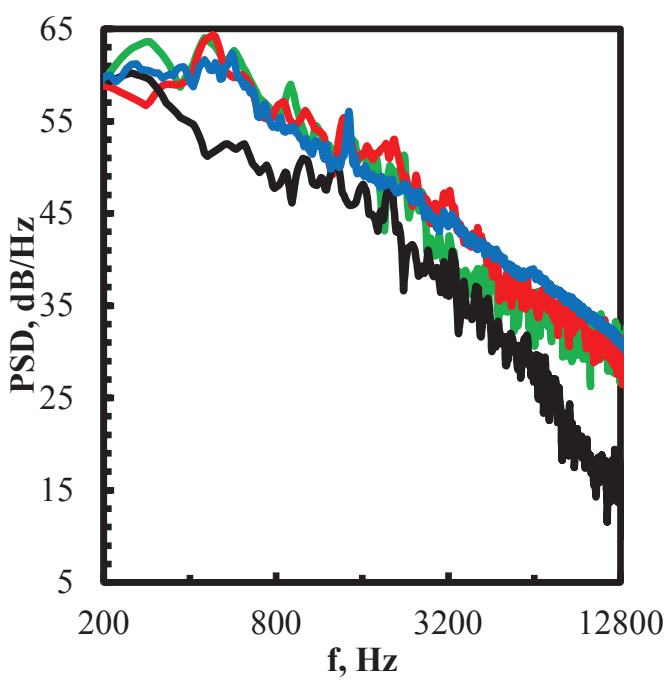

(b)

Figure 8 Power spectral density at Microphone 6: (a) flyover arc, (b) sideline arc.

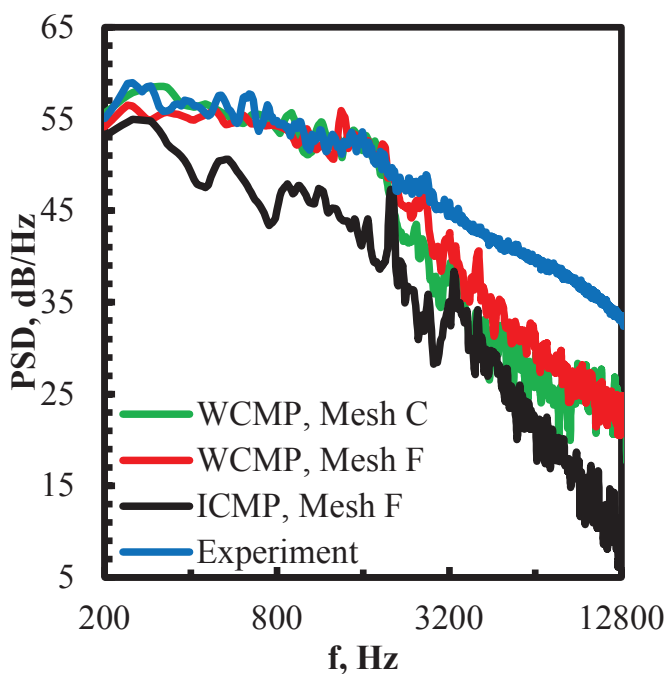

(a)

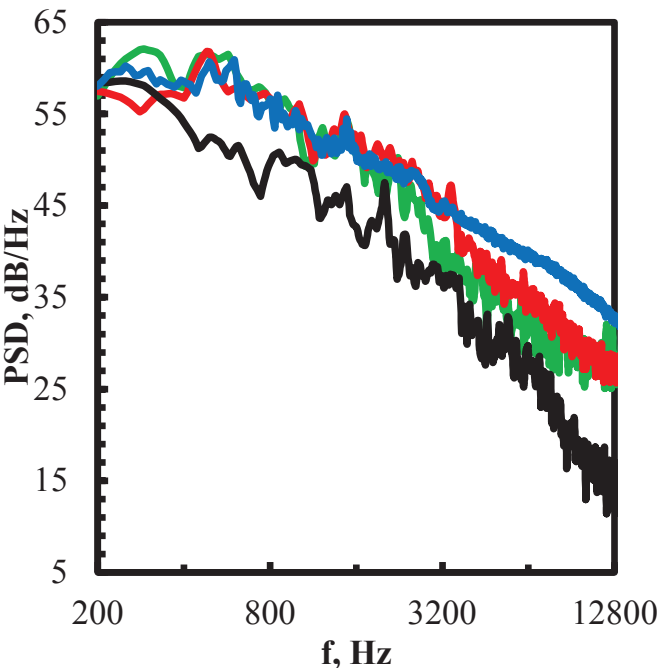

(b)

Figure 9 Power spectral density at Microphone 9: (a) flyover arc, (b) sideline 
Moreover, similar trends have been found compared to simulations performed using other solvers. These trends include: 1) higher cut-off frequencies for far-field noise spectra than those for surface pressure spectra; 2) higher cut-off frequency at overhead and downstream microphones on sideline arc; 3) less under-prediction beyond the cut-off frequency on sideline arc; 4) over-predicted tonal peak at Microphone 3 on sideline arc. For 1) Manoha and Cauelle ${ }^{18}$ gave an explanation that small, local eddies in the near-field that contributed to the surface spectra at higher frequencies are less responsible for far-field noise. For trends 2), 3) and 4) no existing hypotheses are given, but it's suspected that installation effects brought by the mounting plane, the inlet and outlet of the wind tunnel might play a role in it.

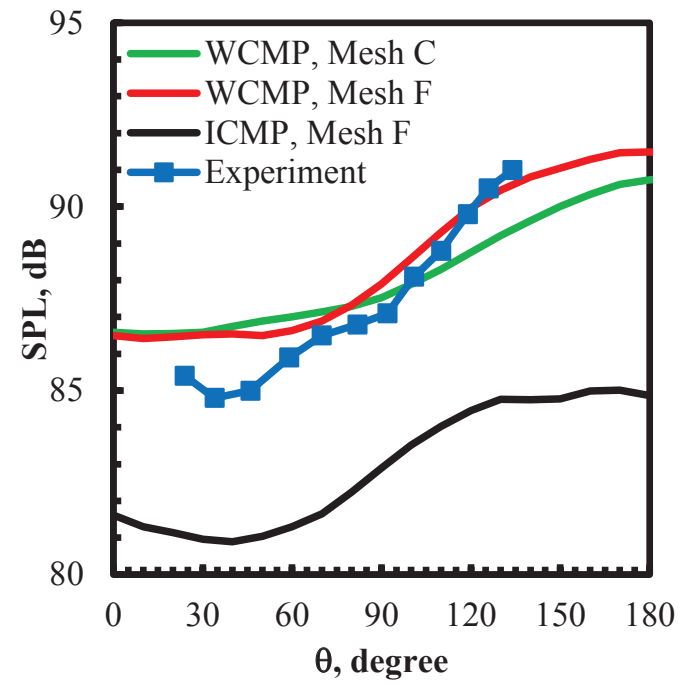

(a)

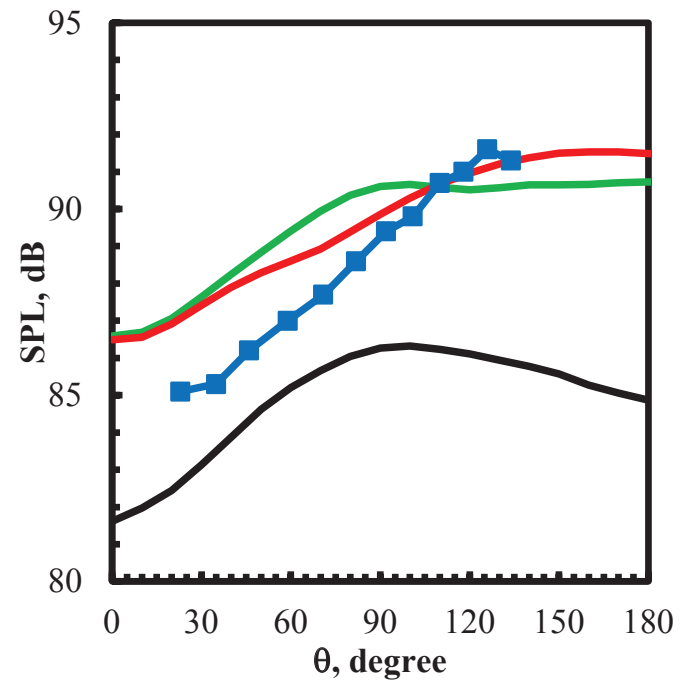

(b)

Figure 10 Overall sound pressure directivity at the positions of all microphones: (a) flyover arc, (b) sideline

Overall sound pressure level (OASPL) directivities on both flyover and sideline arc were calculated by integrating the PSD between $0.2 \mathrm{kHz}$ and $10.0 \mathrm{kHz}$, and are presented with experimental measurements in Figure 10. Again the incompressible predictions severely under-estimate the OASPL by as much as 4 to $6 \mathrm{~dB}$ on the flyover arc and 2 to $5 \mathrm{~dB}$ on the sideline arc, which further confirms that caution must be exercised when using an incompressible solver to predict landing gear noise. In comparison, the weakly compressible predictions are in fairly good agreement with the wind tunnel tests, with a discrepancy of less than $2.5 \mathrm{~dB}$ for most microphone locations. Despite some slight differences, the two meshes of different resolutions also gave similar OASPL, since most of the sound generated is within the low to mid frequency range where both meshes are capable of resolving for this relatively clean landing gear configuration.

\section{IV.E Computational costs}

As mentioned in Section II, the main purpose of using a weakly compressible solver is to reduce the computational cost compared to a fully compressible solver while maintaining the ability to capture flowacoustic coupling phenomena. The results in Section IV successfully confirmed the ability of the solver. Table 1 lists details of computations from different research groups to compare the computational resources of other solvers to the current study. 


\begin{tabular}{|c|c|c|c|c|c|c|c|c|}
\hline CFD solver & OpenFOAM & $\operatorname{elsA}^{720}$ & CFL3D $^{18}$ & SotonCAA ${ }^{6}$ & $\mathrm{AVBP}^{21}$ & $\mathrm{CEDRE}^{22}$ & $\mathrm{LaBs}^{23}$ & $\begin{array}{c}\text { Power- } \\
\text { FLOW }^{19}\end{array}$ \\
\hline Method & $\begin{array}{l}\text { LES + wall } \\
\text { function }\end{array}$ & ZDES & MDDES & DES & LES & ZDES & LBM & $\begin{array}{l}\text { LBM- } \\
\text { VLES }\end{array}$ \\
\hline $\begin{array}{l}\text { Turbulence } \\
\text { model }\end{array}$ & $\mathrm{k}$ equation & S-A & k-w SST & S-A & WALE & k-w SST & $\begin{array}{c}\text { Shear } \\
\text { Improved } \\
\text { Smagorinsky }\end{array}$ & k-e RNG \\
\hline $\begin{array}{l}\text { Space/time } \\
\text { scheme order }\end{array}$ & $2 / 2$ & $2 / 2$ & $2 / 2$ & $6 / 4$ & $3 / 4$ & $2 / 1$ & & D3Q19 \\
\hline Configuration & Slip walls & \multicolumn{2}{|c|}{$\begin{array}{l}\text { Free-field with } \\
\text { floor }\end{array}$} & \multicolumn{4}{|c|}{ Free-field } & $\begin{array}{l}\text { Free-field } \\
\text { with floor }\end{array}$ \\
\hline Grid & Unstructured & \multicolumn{3}{|c|}{ Multi-block structured } & \multicolumn{2}{|c|}{ Unstructured } & \multicolumn{2}{|c|}{ Octree } \\
\hline $\begin{array}{l}\text { Number of } \\
\text { elements }\end{array}$ & 22M(Mesh F) & $34 \mathrm{M}$ & $43.2 \mathrm{M}$ & $15.7 \mathrm{M}$ & $15 \mathrm{M}$ & $61 \mathrm{M}$ & $40 \mathrm{M}$ & $123 \mathrm{M}$ \\
\hline $\begin{array}{l}\text { Min wall cell size } \\
\qquad(1 \mathrm{e}-6 \mathrm{~m})\end{array}$ & 750(Mesh F) & 1 & 0.276 & 30 & 75 & 10 & 500 & 600 \\
\hline $\begin{array}{l}\text { Time step } \\
(1 \mathrm{e}-6 \mathrm{~s})\end{array}$ & 2.5(Mesh F) & 0.5 & 4.971 & 0.87 & 0.3 & 1 & 0.8413 & 0.988 \\
\hline $\begin{array}{l}\text { Storage physical } \\
\text { time }(1 \mathrm{e}-3 \mathrm{~s})\end{array}$ & 100 & 234 & 268 & 143 & 120 & 102 & 337 & 700 \\
\hline $\begin{array}{l}\text { Processor } \\
\text { Number }\end{array}$ & 256(Mesh F) & 256 & 240 & 256 & 600 & 480 & 360 & 272 \\
\hline $\begin{array}{l}\text { Total clock time } \\
\text { (hour) }\end{array}$ & $\begin{array}{c}28.6 \text { (WCMP) } \\
34.2 \text { (ICMP) }\end{array}$ & 1280 & 954 & 600 & 109 & 430 & 60.8 & 76 \\
\hline $\begin{array}{l}\text { Total CPU time } \\
\text { (hour) }\end{array}$ & $\begin{array}{c}\text { 7331(WCMP) } \\
\text { 8758(ICMP) }\end{array}$ & 327680 & 228960 & 204800 & 65000 & 199900 & 21880 & 20780 \\
\hline $\begin{array}{c}\text { CPU/elem/iter } \\
(1 \mathrm{e}-6 \mathrm{~s})\end{array}$ & $\begin{array}{c}\text { 28.7(WCMP) } \\
\text { 36.2(ICMP) }\end{array}$ & 74.1 & 354 & 286 & 39.0 & 115.1 & 4.93 & 0.137 \\
\hline
\end{tabular}

Table 1 Main features of CFD numerical methods, solvers, grids and computation time. The results of the simulation presented in this paper are in the first column.

In this study, the weakly compressible solver is faster than the incompressible solver. A closer examination shows that fewer loops inside the PISO algorithm were performed per time step in the weakly compressible computation, thus saving computational time. When compared with other solvers, it can be seen that the CPU time per element per iteration is lower than all other fully compressible Navier-Stokes solvers, which confirms the advantage of using the weakly compressible formulations by eliminating the energy equation in low-Mach number flows. Even though the weakly compressible solver performs better than all other Navier-Stokes solvers, using this criterion of performance it is still significantly slower than solvers applying the Lattice Boltzmann Method (LBM). It should also be noted that the data above doesn't include different methods' dissipation, which is very important to resolve mid- and high-frequency contents of an actual, complex landing gear. 


\section{Summary and Future Work}

Numerical simulations of the LAGOON \#1 landing gear configuration were performed using a weakly compressible solver. Another simulation using an incompressible solver was also performed for comparison. Predictions of both near-field flow features and far-field acoustics were compared with experimental measurements, so that the capability of the weakly compressible solver and limitations of the incompressible solver could be investigated. To study grid sensitivity effects two meshes of different resolutions were used. A one-equation LES sub-grid model was used with a wall function to model the sub-grid scale turbulence, and a solid FW-H integration surface was used to calculate the far-field noise.

For time-averaged and RMS flow variables, predictions by the weakly compressible simulations were very close to those using the incompressible solver, and were found to be in reasonable agreement with wind tunnel measurements. On-surface pressure spectra showed that the weakly compressible solver was capable of predicting cavity tones that were absent using an incompressible solver. Moreover, at several Kulite locations in the experiments, the broadband contents were significantly under-predicted by the incompressible solver. Between the two grids, the finer (Mesh F) predicted a higher cut-off frequency than the coarser mesh (Mesh C), while the time-averaged and RMS flow variables both on the landing gear surface and in the near wake analysed in this study converged towards the experimental measurements.

In the far-field, the incompressible solver failed to predict both tonal and broadband noise. The computed spectra by the incompressible simulation under-predicted the noise throughout the entire frequency range. In comparison, the predicted frequencies and amplitude of the cavity resonant tones by the weakly compressible simulations, as well as broadband contents, were in good agreement with the experimental measurements. As a result, the under-prediction of OASPL by the incompressible solver was greatly improved by using the weakly compressible formulation. Using a finer mesh resolution increased the cut-off frequency of the far-field noise spectra for the on-surface pressure spectra. The cut-off frequencies for the far-field noise were found to vary with microphone locations and were higher than their on-surface counterparts.

In terms of computational efficiency, the weakly compressible solver was found to be faster than the incompressible solver, as well as other fully compressible Navier-Stokes solvers in existing literature that studied the same landing gear configuration. However, it was still significantly slower than Lattice Boltzmann solvers, if the CPU time per element per iteration was chosen to be the criterion. However, since the mesh topology and resolution, time steps, turbulence models and accuracy obtained for near- and far-field flow/acoustic variables vary a lot between studies, such a case-to-case comparison of computational efficiency is thought to be quite crude, and further investigation is still needed.

Even though an incompressible solver gave satisfactory predictions of the mean flow variables around a landing gear, its ability to capture the correct tonal and broadband features of both on-surface pressure and farfield noise spectra was limited, due to its inability to resolve flow-acoustic coupling phenomena. In contrast, the weakly compressible formulation was able to resolve the flow-acoustic interaction, at a reduced cost compared to a fully compressible Navier-Stokes solver. However, more rigorous study towards the accuracy and efficiency of this solver is still needed for an actual landing gear with more complex geometry.

\section{Acknowledgement}

Yu Hou would like to thank the University of Southampton and China Scholarship Council (CSC) for providing financial support for this research. The authors would also like to thank Airbus for the technical and financial support for this work.

\section{References}

${ }^{1}$ Hedges, L. S., Travin, A. K. and Spalart, P. R., "Detached-Eddy Simulations over a Simplified Landing Gear," Journal of Fluids Engineering, 124(2), pp. 413-423, 2002.

${ }^{2}$ Khorrami, M. R. and Lockard, D. P., "Landing Gear Noise Reduction Study Based on Computational Simulations," in INTER-NOISE 2006, Honolulu, 2006.

${ }^{3}$ van Mierlo, K. J., Takeda, K. and Peers, E., "Computational Analysis of the Effect of Bogie Inclination Angle on Landing Gear Noise," AIAA 2010-3971, in 16th AIAA/CEAS Aeroacoustics Conference, Stockholm, 2010 .

${ }^{4}$ Vasta, V. N., Lockard, D. P., Khorrami, M. R. and Calson, J. R., “Aeroacoustic Simulation of a Nose Landing Gear in an Open Jet Facility Using FUN3D," AIAA 2010-4001, in 16th AIAA/CEAS Aeroacoustics Conference, Stockholm, 2010.

${ }^{5}$ Wang, M., Angland, D. and Zhang, X., "The Noise Generated by A Landing Gear Wheel with Hub and Rim Cavities," Journal of Sound and Vibration, 392, pp. 127-141, 2017. 
${ }^{6}$ Liu, W., Kim, J. W., Zhang, X., Angland, D. and Caruelle, B., "Landing-Gear Noise Prediction using HighOrder Finite Difference Schemes," Journal of Sound and Vibration, 332(14), pp. 3517-3534, 2012.

${ }^{7}$ Sanders, L., Manoha, E., Ben Khelil, S. and Francois C., "LAGOON : CFD/CAA Coupling for Landing Gear Noise and Comparison with Experimental Database," AIAA-2011-2822, in 17th AIAA/CEAS Aeroacoustics Conference, Portland, 2011.

${ }^{8}$ Turkel, E., "Review of Precondictiong Methods for Fluid Dynamics," Applied Numerical Mathmatics, 12, pp.257-284, 1993.

${ }^{9}$ Inagaki, M, Murata, O., Kondoh, T. and Abe, K., "Numerical Prediction of Fluid-Resonanat Oscillation at Low Mach Number,” AIAA Journal, 40(9), pp. 1823-1829, 2002.

${ }^{10}$ Wang, Y., Lee, H. C., Li, K. M., Gu Z. and Chen, J., "Experimental and Numerical Study of Flow over a Cavity for Reduction of Buffeting Noise,“ Acta Acustica united with Acustica, 98(4), pp. 400-610, 2012.

${ }^{11}$ Issa, R., "Solution of the Implicitly Discretized Fluid Flow Equations by Operator Splitting," Journal of Computational Physics, 62, pp. 40-65, 1985.

${ }^{12}$ Yoshizawa, A. and Hriuti, K., "A Statisctically-Derived Subgrid-Scale Kinetic Energy Model for the Large-Eddy Simulation of Turbulent Flows," Journal of the Physical Society in Japan, 54(8), pp. 2834-2839, 1985.

${ }^{13}$ Afzal, N, "Wake Layer in a Turbulent Boundary Layer with Pressure Gradient: a New Approach," in IUTAM Symposium on Asymptotic Methods for Turbulent Shear Flows at High Reynolds Number., pp. 95-118, 1996.

${ }^{14}$ Hou, Y., Angland, D. and Zhang, X., "A Comparison of Wall Functions for Bluff Bluff Body Aeroacoustic Simulations," AIAA 2016-2771, in 22 ${ }^{\text {nd }}$ AIAA/CEAS Aeroacoustics Conference, Lyon, 2016.

${ }^{15}$ OpenFOAM. OpenFOAM Programmer's Guide Version 2.2.2, 2013.

${ }^{16}$ OpenFOAM, OpenFOAM User Guide Version 2.2.2, 2013.

${ }^{17}$ Manoha, E., Bulte, J and Caruelle, B., "LAGOON: an Experimental Database for the Validation of CFD/CAA Methods for Landing Gear Noise Prediction," AIAA 2008-2816, in 14th AIAA/CEAS Aeroacoustics Conference, Vancouver, 2008.

${ }^{18}$ Manoha, E. and Caruelle, B., "Summary of the LAGOON Solutions from the Benchmark problems for the Airframe Noise Computations-III Workshop," AIAA 2015-2846, in 21st AIAA/CEAS Aeroacoustics Conference, Dallas, 2015.

${ }^{19}$ Casalino, D., Ribeiro, A., Fares, E. and Nolting, S., "Lattice-Boltzmann Aeroacoustic Analysis of the LAGOON Landing-Gear Configuration,” AIAA Journal, 52(6), pp. 1232-1248, 2014.

${ }^{20}$ Sanders, L., Manoha, E., Ben Khelil, S. and Francois, C., "LAGOON: New Mach Landing Gear Noise Computaion and Further Analysis of the CAA Process," AIAA 2012-2281, in 18th AIAA/CEAS Aeroacoustics Conference, Colorado Spring, 2012.

${ }^{21}$ Giret, J., Sengissen, A., Moreau, S. and Jouhaud, J., "Prediction of LAGOON Landing-Gear Noise using an Unstructured LES Solver," AIAA 2013-2113, in 19th AIAA/CEAS Aeroacoustics Conference, Berlin, 2013.

${ }^{22}$ De la Puente, F., Sanders, L. and Vuillot, F., “ On LAGOON Nose Landing Gear CFD/CAA Computation over Unstructured Mesh using a ZDES approach," AIAA 2014-2763, in 20th AIAA/CEAS Aeroacoustics Conference, Atlanta, 2014

${ }^{23}$ Sengissen, A., Giret, J., Coreixas, C. and Boussuge, J., "Simulations of LAGOON Landing-Gear Noise using Lattice Boltzmann Solver," AIAA 2015-2993, in 21st AIAA/CEAS Aeroacoustics Conference, Dallas, 2015. 